() 2018 - ISSN 1807-2577

\title{
Biomechanical development and evaluation of a new framework for all-on-four rehabilitation
}

\author{
Desenvolvimento e avaliação biomecânica de uma nova infraestrutura para \\ reabilitações "all-on-four"
}

\author{
Vanessa Araujo SILVA* ${ }^{a *}$, Allyson Henrique de Andrade FONSECA ${ }^{a} \mathbb{D}^{\mathbb{D}}$, \\ Dimitri Ribas FONSECA ${ }^{\mathrm{b}}$ (in memoriam), Paulo Isaías SERAIDARIAN ${ }^{\mathrm{a}}$ (i) \\ aPUC Minas - Pontifícia Universidade Católica de Minas Gerais, Departamento de Odontologia, Belo Horizonte, MG, \\ Brasil \\ bUFVJM - Universidade Federal dos Vales do Jequitinhonha e Mucuri, Departamento de Odontologia, Diamantina, MG, \\ Brasil
}

\begin{abstract}
How to cite: Silva VA, Fonseca AHA, Fonseca DR, Seraidarian PI. Biomechanical development and evaluation of a new framework for all-on-four rehabilitation. Rev Odontol UNESP. 2019;48:e20180123. https://doi.org/10.1590/18072577.12318
\end{abstract}

\section{Resumo}

Introdução: Para reabilitação de mandíbulas totalmente edêntulas, a opção por carga imediata determina a utilização de próteses provisórias que esplintem os implantes instalados. Apesar de provisórias com reforço proverem as reabilitações com benefícios biomecânicos, a não adoção desta indicação coexiste em diferentes estudos sobre restaurações imediatas. Objetivo: Este estudo avaliou um tipo de prótese para reabilitar mandíbulas pelo conceito "all-on-four". Material e método: Foi avaliado, in-vitro, o comportamento mecânico de próteses com a infraestrutura modificada, sob ensaio mecânico de flexão unilateral em cantilever. Foram avaliados dois grupos representativos para o conceito "all-on-four", sendo um grupo teste G1 ( $\mathrm{n}=10)$ contendo próteses com infraestrutura modificada e outro controle G2 $(\mathrm{n}=10)$ que incluiu próteses totalmente acrílicas. As amostras foram submetidas à ciclagem térmica com 500 ciclos $\left(5^{\circ} \pm 2{ }^{\circ} \mathrm{C}\right.$ por 30 segundos e $55^{\circ} \pm 2{ }^{\circ} \mathrm{C}$ pelo mesmo tempo $)$ e submetidas ao ensaio mecânico à flexão sobre o cantilever. Resultado: 0 teste de Mann-Whitney revelou diferença significativa entre G1 e G2 $(p<0,001)$. $\mathrm{Na}$ avaliação descritiva, G1 mostrou média de 830,50 N até a fratura inicial em resina e o grupo controle apresentou média de 403,58N. A resistência máxima até a fratura completa foi de 903,03 N para G1 e para G2 de 435,20 N. 0 componente vertical linear de flexão foi 0,68 mm e 0,39 mm até a fratura inicial da barra, respectivamente para G1 e G2. Conclusão: A infraestrutura modificada para o protocolo "all-on-four" proporcionou melhor desempenho mecânico quando comparado ao mesmo modelo de prótese totalmente acrílico.

Descritores: Carga imediata em implante dentário; mandíbula; infraestrutura; implantes dentários.

\begin{abstract}
Introduction: For complete rehabilitation of fully edentulous mandibles, the option for immediate loading determines the use of temporary prostheses that splint the installed implants. Although temporary prostheses with reinforcement provide rehabilitations with biomechanical benefits, the non-adoption of this recommendation coexists in different studies on immediate restorations. Objective: This study evaluates a type of prosthesis to restore jaws by the all-on-four concept. Material and method: The mechanical behavior of prostheses with the modified framework was evaluated in vitro, under a cantilever mechanical unilateral bending test. Two representative groups were included in the all-on-four concept, with a G1 test group $(n=10)$ containing modified frameworks and a G2 control group $(n=10)$ that included full acrylic prostheses. The samples were submitted to thermal cycling with 500 cycles $\left(5^{\circ} \pm 2{ }^{\circ} \mathrm{C}\right.$ for $30 \mathrm{~s}$, and $55^{\circ} \pm 2^{\circ}$ for $\left.30 \mathrm{~s}\right)$ and to the mechanical bending test on the cantilever. Result: The Mann-Whitney test revealed a significant difference between G1 and $\mathrm{G} 2(\mathrm{p}<0.001)$. In the descriptive evaluation, G1 averaged $830.50 \mathrm{~N}$ until the initial resin fracture, while the control group presented a mean of 403.58N. The maximum resistance until complete fracture was recorded in G1, with
\end{abstract}


a mean of $903.03 \mathrm{~N}$, while in G2, a mean of $435.20 \mathrm{~N}$ was recorded. The linear vertical component of the flexion was $0.68 \mathrm{~mm}$ and $0.39 \mathrm{~mm}$ until the initial fracture of the bar, respectively for G1 and G2. Conclusion: The modified framework for the all-on-four protocol determined better mechanical performance when compared to the same full acrylic prosthesis model.

Descriptors: Immediate loading on dental implant; mandible; framework; dental implants.

\section{INTRODUCTION}

The all-on-four concept (Nobel Biocare, Gothenburg, Sweden), a rehabilitation modality that combines axial anterior and angled posterior implants with immediate load on the mandible, has been validated by longitudinal studies ${ }^{1,2}$. Since it was developed by Maló et al. ${ }^{3}$, the surgicalprosthetic technique has shown excellent results and predictable success rates ${ }^{4-6}$.

After 5-year and 10-year follow-ups, implant success rates of $98.1 \%$ and $94.8 \%$, respectively, were observed. Excellent results were also obtained in biomechanical evaluations of prosthetic rehabilitation of the edentulous mandible, by means of the all-on-four concept ${ }^{2}$. By using four implants, balanced by greater spacing among them, the expected polygonal setup is maintained, ensuring sufficient biomechanical stability to the prosthesis, and appropriate force distribution to bone ${ }^{5,7-9}$.

Advantages of this concept include the possibility of using long implants and the reduced need for bone graft ${ }^{8}$. The prevention of long cantilevers, as well as the possibility of increasing the distance between anterior and posterior pillars, characterize the significance of the proposal ${ }^{9,10}$. Other advantages include a lower cost and easier cleaning, due to the reduced number of implants $^{5,11}$.

However, different studies report on prosthetic complications and temporary acrylic prosthesis breaks during the post-surgery recovery phase ${ }^{4,5,9,10}$. The choice to prepare the temporary prosthesis without internal reinforcement contributes to the occurrence of complications varying between $10.8 \%$, according to Hinze et al. ${ }^{5}$ and $30 \%$ reported on Maló et al. $^{3}$ study, whereas the temporary prostheses, with internal reinforcement, are considered to be the golden standard as they offer biomechanical advantages ${ }^{11}$. The metal framework promotes rigid splinting and maintains implant micromovements below the critical threshold, favoring osseointegration $^{12}$. The prosthesis metal reinforcement hinders fracture and may also reduce bending forces, decreasing bone stress and favoring the required hardness during the implant scarring phase ${ }^{8}$.

However, a quality metal reinforcement, ensuring a passive fit of the prosthesis, requires more time and adds to the financial costs of rehabilitation ${ }^{1}$. Alternatives for planning effective frameworks have been discussed in several studies ${ }^{8,12-15}$. Despite the advances, no evidence has been observed ${ }^{4,6,8,11}$ that complement the simplicity proposed by Maló et al. ${ }^{2,3}$.

The present study proposes a new type of immediate prosthesis for the all-on-four protocol, consisting of non-welded metal structure, designed to offer an in vitro view of mechanical behavior of these prostheses regarding their fracture resistance, when compared to fully acrylic prostheses without internal reinforcement.

\section{MATERIAL AND METHOD}

Two sets of test specimens have been compared, one test group named G1 ( $\mathrm{n}=10)$, and the other, G2 $(n=10)$. G1 included prostheses with a metal framework in non-welded cobalt- 
chromium alloy, cast and machined separately from the support cylinder and later combined with machined and pre-fabricated titanium cylinders during the acrylic press. G2 consisted of fully acrylic prostheses for the all-on-four protocol.

Previous waxing and mounting of the acrylic teeth were performed in order to reproduce the ideal tooth distribution, in a full Brånemark protocol mandibular prosthesis, allowing for the adjustment of the implant geometry and positioning. Based on this waxing, a diagnostic model was developed, in heat activated acrylic resin, containing four analogs of mini conical pillars with a 4.1-mm platform, a 3-mm band, and 20-degree convergence (Neodent, Curitiba, PR, Brazil). The two anterior analogs were positioned perpendicularly to the areas corresponding to the cingulum of the lateral incisors, and the two posterior analogs were positioned in the second pre-molar region, in accordance with Maló et al. ${ }^{3}$ protocol. To simulate the immediate post-surgical clinical status, after inserting the prosthetic mini-pillars, the diagnostic model posterior analogs were inserted without inclination for the prosthetic platform parallel to the occlusal plane to represent the distal implant angle (30 degrees).

By means of a transference index (Figure 1a), with molding components consisting of metal stems connected by low contraction acrylic, the position of prosthetic components was transferred to a carbon steel metal disc, constituting the metal master model (MM) (Figure 1b). The MM was prepared to also be coupled to the trial machine, working as a support for the mechanical test. With the aid of the AutoCAD 2007 software (Autodesk, California, USA), a metal structure was prepared for prosthetic reinforcement that was compatible with the all-on-four protocol (Figure 1c), adopting the following dimensions: $2.0-\mathrm{mm}$ gingival-occlusal width, $6.8-\mathrm{mm}$ vestibular-lingual width, and $10-\mathrm{mm}$ cantilever. Four circular $4.9 \mathrm{~mm}$ diameter drills were designed to insert the support cylinders (Neodent, Curitiba, PR, Brazil). With this diameter, the framework ran through the conical shape of the cylinders, with a cervical shoulder fit and a 0.6-mm support around the entire opening. After the layout was completed, the framework was printed in 3D with the support of a SD 300 Pro printer (SKA, Tel Aviv, Israel).

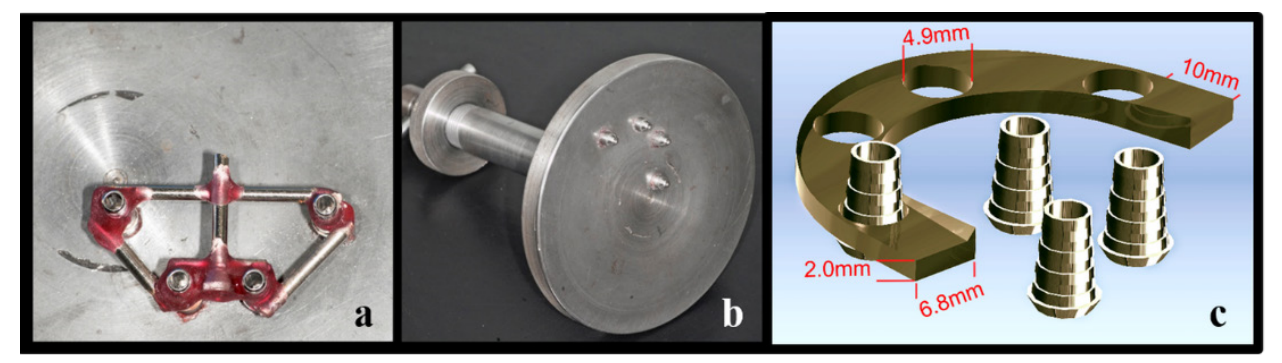

Figure 1. (a) Transfer index image; (b) Master model (MM); (c) CAD design model for the metal bar.

From the prototype, it was possible to develop a metal matrix (M0) designed to reproduce the resin patterns under press (Pattern Resin LS GC, Tokyo, Japan) for the future metal frameworks (Figure 2a). After dimensions have been checked with the help of a caliper, 20 acrylic frameworks were selected to constitute both experimental groups. For the G1, ten frameworks have been processed and cast in cobalt-chrome (Co-Cr) alloy (Figure 2b). For the G2, ten acrylic patterns were reserved, free of any processing.

The prosthesis section designed to press the resin was reproduced over two other matrices (M1 and M2) (Figure 2a). The M1 enabled the positioning of the G1 frameworks, and M2 was prepared to control the G2. The M1 was different as it spaced the framework at $1.5 \mathrm{~mm}$ from the cylinder shoulder, whereas in M2, the structures came in contact with each other. Both matrices bore implant analogs to be bolted to the cylinders when the prostheses are mounted.

Both matrices allowed for the mounting of the prototypes in wax, with a $6.8-\mathrm{mm}$ vestibular-lingual width and a $6.9-\mathrm{mm}$ cervical-occlusal height, including titanium frameworks and cylinders (Figures 2c and 2d). In M1, rubber rings were inserted (1.5 $\mathrm{mm}$ ) 
over the titanium cylinder shoulder to ensure homogeneity between the spacing and the bars (Figure 2c).

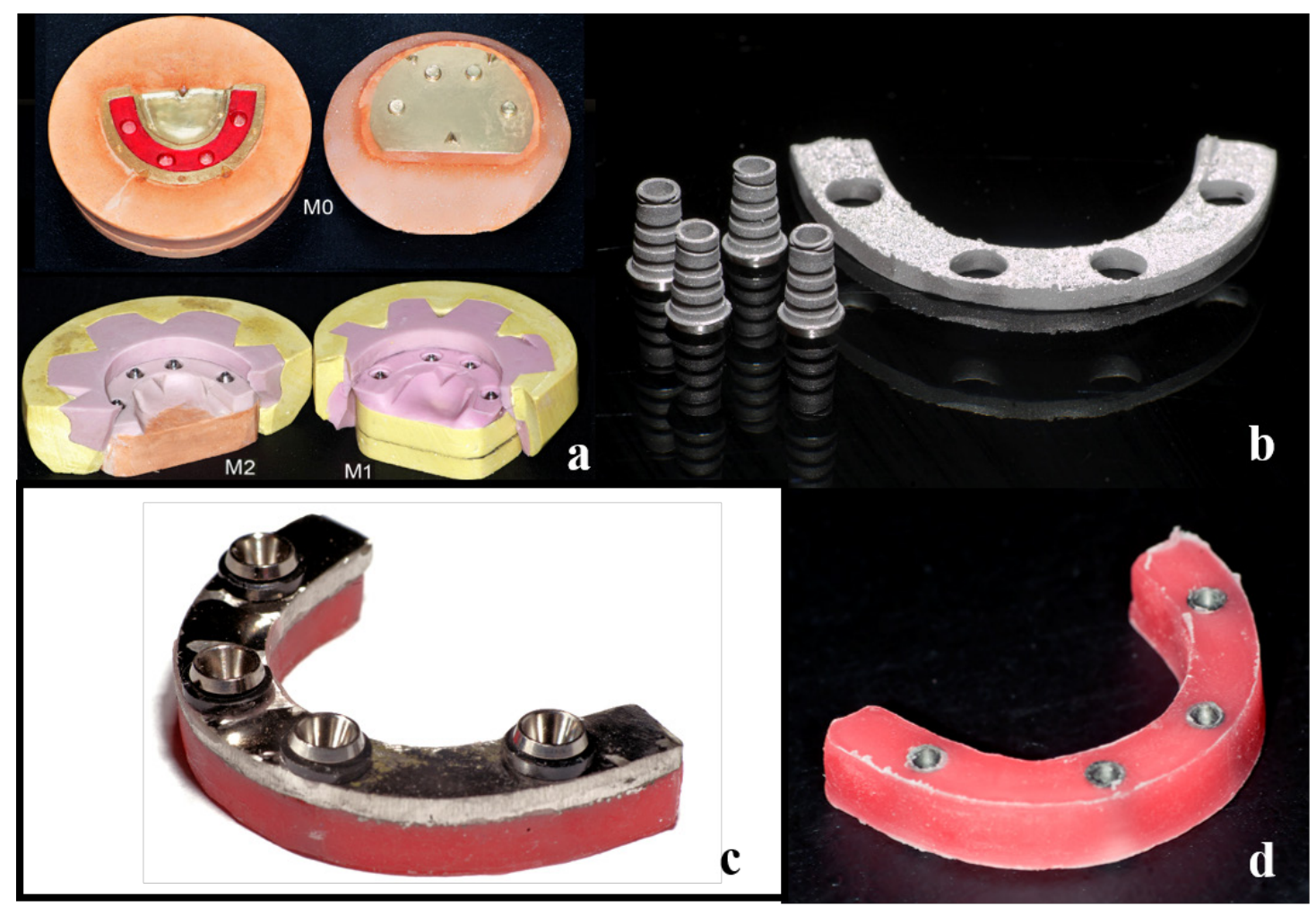

Figure 2. (a) Matrices; (b) non-welded metal bars; (c) G1 test specimen in wax; (d) G2 test specimen in wax.

After being verified with a caliper, the prototypes were bolted onto twenty models, constituting copies of the MM model, with titanium analogs and bases in type IV gypsum stone (Herostone, Vigodente, RJ, Brazil). In sets of four units, the models with their respective prototypes were included in muffle. After a gypsum press time of approximately 30 minutes, the muffle was taken to a microwave oven (LG 1200W, LG Electronics, SP, Brazil) for one minute and twenty seconds to melt the wax. After full wax removal, the pre-fabricated cylinders were cleaned with a brush and blasted with 125-micrometer particles of aluminum oxide, and once again bolted to the models included in the muffles. G1 frameworks were also blasted with aluminum oxide. Microwave power activated resin powder and liquid (VipWave, Vip, São Paulo, SP, Brazil) were proportioned according to the manufacturer's instructions and deposited inside the muffle, which was pressed at 1 ton for 20 minutes. Following manufacturer's instructions for full acrylic polymerization, in the initial stage, the muffle was maintained for 20 minutes at a $10 \%$ to $20 \%$ power in a microwave oven, and in the final stage, for 5 minutes at a $30 \%$ to $40 \%$ power.

The spacing between the support cylinder metal bar and the shoulder in the G1 group, after polymerization, enabled the formation of a resin collar that connected these structures. After unmuffling, the test specimens were cleaned with a brush and stored in water at $37^{\circ} \pm 1^{\circ} \mathrm{C}$ until thermal cycling.

The test specimens were bolted to a different model, also originated from the MM, and ten-unit groups were subjected to 500 cycles in a thermocycler (MSCT/3e-ELQUIP, São Paulo, SP, Brazil). Each cycle consisted of 30 -second baths, alternating in water at $5^{\circ} \pm 2^{\circ} \mathrm{C}$ and $55^{\circ} \pm 2{ }^{\circ} \mathrm{C}$. When the thermal cycling was completed, the test specimens were evaluated visually by means of a stereoscopic magnifier, STEMI 2000-C (Zeiss, Germany), 20x magnification, by a duly calibrated examiner, who did not observe apparent damages in the test specimens. After the thermal cycling, the test specimens were stored again in water at $37^{\circ} \pm 1^{\circ} \mathrm{C}$. 
The MM was coupled to a universal tester (EZTest 5kN, EZ-L, Shimadzu, Japan); here the G1 and G2 test specimens were individually bolted at $20 \mathrm{~N}$ torque in each titanium bolt. A loading piston was positioned over the right cantilever, $5 \mathrm{~mm}$ apart from the bar distal edge, exerting a compressive axial force with a maximum limit of $1,000 \mathrm{~N}$. The applied speed was $0.5 \mathrm{~mm} / \mathrm{minute}$ until the test specimen was fractured, or until it reached the maximum load (Figure 3).

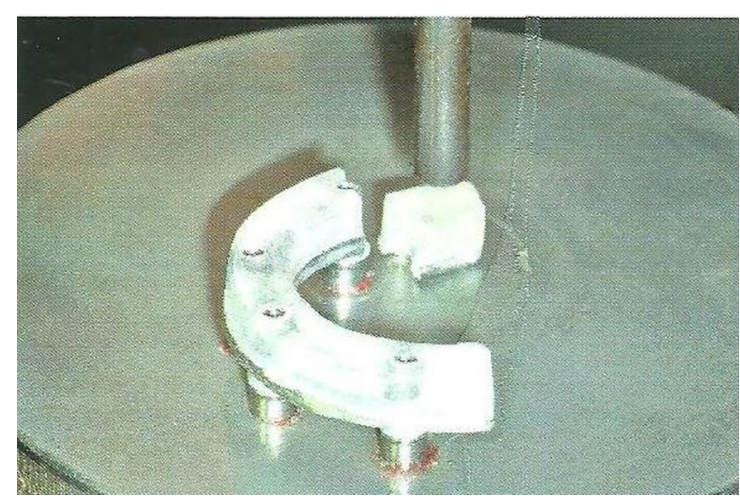

Figure 3. G1 test specimen after fracture.

The mechanical behavior data for the sample were recorded, and the analysis was performed using the software SPSS version 13.0 for Windows (SPSS Inc., Chicago, IL). Descriptive statistical analyses were developed for the following dependent variables: maximum supported load until the initial resin fracture, linear extension of deformation, and maximum withstood load until full fracture.

\section{RESULT}

Thermal cycling, under evaluation with a magnifier, produced no apparent damages in the test specimens. The bending test caused full fractures in the test specimen cantilevers that propagate through the vestibular-lingual interface, adjacent to the distal cylinder, in a cross section of the bar (Figure 3). Initial fractures (FI) occurred in the resin, which, as the test progressed, became full of fractures (FC), characterized by the sudden tension drop recorded by the trial machine software.

Figure 4 presents the deformation charts (\%) and applied load $(\mathrm{N})$ generated in the Universal Tester, with evidence of initial fracture (FI) and complete fracture (CF). Table 1 presents the descriptive analysis of the dependent variables. The Mann Whitney test revealed statistical significance in the inter-group comparison for the withstood load until initial resin fracture $(p<0.001)$, maximum applied load $(p<0.001)$, as well as in the vertical-linear component of the cantilever bending $(p<0.001)$. 


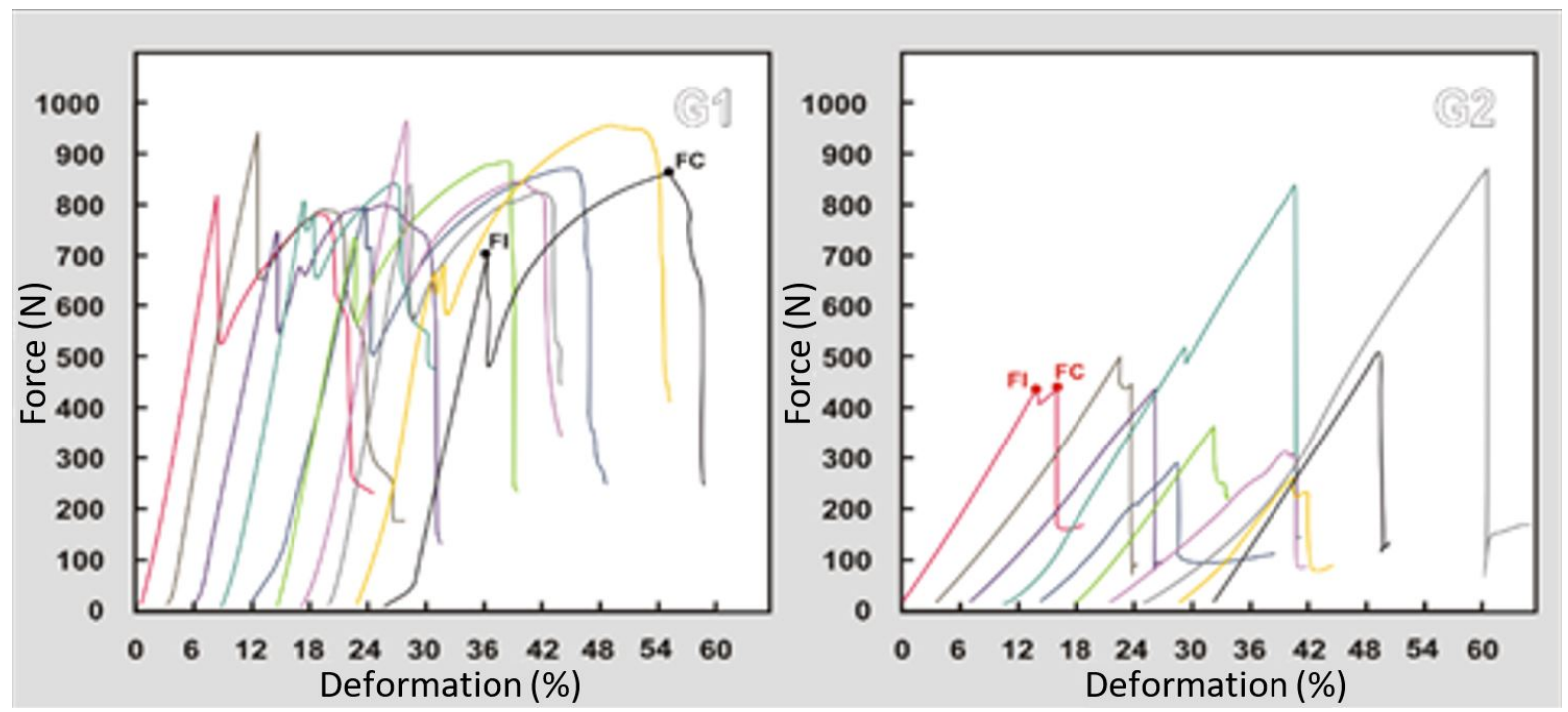

Figure 4. Deformation chart (\%) and applied load (N), recorded for G1 and G2.

In G1, simultaneous resin and metal fractures occurred and all metal frameworks broke with minimum loads above $821 \mathrm{~N}$ and maximum loads of $993.75 \mathrm{~N}$. For G2, all bars broke with a minimum load of $275.43 \mathrm{~N}$ and a maximum load of $798.50 \mathrm{~N}$.

Table 1. G1 and G2 mechanical behavior analysis $(n=10)$

\begin{tabular}{|c|c|c|c|c|c|}
\hline & Average & (SD) & Minimum & Maximum & Median \\
\hline \multicolumn{6}{|c|}{ Maximum load up to initial fracture (N) } \\
\hline G1 & 830.50 & 95.96 & 704.25 & 993.75 & 836.38 \\
\hline G2 & 403.58 & 81.80 & 275.43 & 495.73 & 417.89 \\
\hline \multicolumn{6}{|c|}{ Maximum load evaluated (N) } \\
\hline G1 & 903.03 & 59.61 & 821.75 & 993.75 & 890.50 \\
\hline G2 & 435.20 & 147.78 & 275.43 & 798.50 & 419.30 \\
\hline \multicolumn{6}{|c|}{$\begin{array}{l}\text { Vertical component of the cantilever } \\
\text { bending up to the initial fracture }(\mathrm{mm})\end{array}$} \\
\hline G 1 & 0.68 & 0.11 & 0.59 & 0.90 & 0.63 \\
\hline G2 & 0.39 & 0.10 & 0.28 & 0.58 & 0.36 \\
\hline
\end{tabular}

\section{DISCUSSION}

The success of the all-on-four concept has been clinically reviewed for the survival rate of implants $^{2,3,5,9,10,12,16}$, despite the occurrence of prosthetic complications, ranging from $10.8 \%$ to $30 \%$ in full temporary prostheses, for edentulous mandible rehabilitation ${ }^{1,3,5,10}$. The highest occurrence rates were found in works that used no reinforcement structure for the prostheses ${ }^{1,3}$. Similarly, in the present study, bending load resistance differences between G1, with metal framework, and G2, without such reinforcement, were significant.

Figure 4 shows that, in G1, there was greater load absorption, with a lower percentage of deformation. At the start of deformation, the lines corresponding to each test specimen are noticeably steeper, when compared to G2. The behavior in G1 reveals greater hardness, as the $\mathrm{N} / \mathrm{m}$ ratio is higher when compared to $\mathrm{G} 2{ }^{17}$. 
Although Maló et al. ${ }^{3}$ have reported that the prosthetic failures recorded were repairable and had no effect on survival rates, this study detected full fractures on the cantilever end. When they occur clinically, full fractures require unbolting the prosthesis for repair, within the scarring period between 4 and 6 weeks, when operating with an immediate load ${ }^{18}$. Early removal may lead to counter-torque exceeding the resistance of the bone being remodeled, and may interfere in osseointegration $^{2,12}$. Therefore, the metal framework reviewed in this study, may contribute to the elimination of future prosthetic problems.

Several studies ${ }^{1,5,9,10}$ make no reference to the use of metal framework, nor do they discuss the evidence obtained from excluding the reinforcement. The decision made may arguably have been influenced by the difficulty in developing, during the immediate post-surgical period, a quality, low-cost framework that allows for resistance and passive adaptation.

Bending resistance is known to evaluate the maximum bending the material may withstand before fracture ${ }^{19}$. Taking into account the occurrence of free distal extension, subjected to the masticatory function, bending resistance becomes a relevant clinical factor in all-on-four rehabilitations.

The proposal of a design that would provide spacing between the metal bar and the support cylinder shoulder, allowing, after pressing, for the formation of a resin collar that would join these structures, sought greater occlusal load absorption and better dissipation among the implants, avoiding direct contact between metals. Studies that evaluated stress concentrations on full prosthesis upon the edentulous mandible revealed an overload on the distal implant ${ }^{4,6}$. Even when distal angled implants were selected, with the possibility of a stress concentration reduction of up to $17 \%$, the stress accumulation for cantilever adjacent implants still persists ${ }^{20}$.

The metal bar design with structural modification allowed for the assembly to reach a bending linear-vertical component of $0.68 \mathrm{~mm}$ up to the initial fracture for G1 test specimens. An increase in this bending linear extension reached $74.36 \%$, which was deemed satisfactory when compared to the G2. All fractures, however, occurred in the distal interface of the last implant, which confirms the stress concentration shown in findings from Begg et al. ${ }^{6}$ on distal implant biomechanics.

In designs, including a bar isolated from the cylinders, exhibiting relative spatial freedom between them and the framework, the resistance element under observation in this study becomes the interface between the resin, the cylinder, and the metal bar. Therefore, this study proposed the evaluation of all bars with resin subjected to thermal cycling ${ }^{21}$, simulating the assembly thermal fatigue. Even with thermal aging, the results of absorbed load up to the initial fracture were higher than those of the control group, and higher than the average observed in other studies ${ }^{4,6}$.

The prosthesis evaluated in G1 withstood the occlusal load on the cantilever (830.50N) up to the initial resin fracture. Taking into account that the occlusal load recorded on the molar region in patients with implant treatment showed a variation ranging between $112.5 \mathrm{~N}$ and $450 \mathrm{~N}^{22-24}$, the resistance increment for the framework proposed in this study may be valued. Similarly, the G2 control group withstood the bending load (403.58N), a value close to those found in previous works ${ }^{1,5,9,10}$ regarding the occlusal load and may explain a greater occurrence of failure in prosthesis without reinforcement bars.

The bar allowed for the exclusion of metal welding ${ }^{12,13}$, as they were cast in a single block. Casting the structure, independently from the cylinders, contributed to the absence of influence of metal alloy cooling contraction and casting failures inherent to the process of obtaining conventional frameworks in prosthetic adaptation in the present study, considering the connection to the cylinders took place during the pressing phase. During this stage, placing the cylinders over the master model provided better control of its position. 
In the present study, the master model copy (M1) was the basis for pressing the prostheses. The cylinders and the metal bar were fastened to this model, ensuring fidelity to the MM after pressing. Therefore, for the clinical use of this proposal, it would be important to obtain faithful models of the implant distribution in the mouth. The option to use the transference index with auxiliary metal bars and low acrylic contraction was based on work showing satisfactory results with this technique ${ }^{25}$.

The G2 group exhibited initial fractures under lower loads other than those observed in the G1 group. The lowest mechanical resistance observed in the fully acrylic bar proves the findings in the clinical study conducted by Maló et al. ${ }^{3}$ Despite the fracture rates reported in different studies and this control group behavior, structures that are not fully acrylic are still mentioned in restoration protocols for the edentulous mandible $5,9,10,26$.

Only two clinical post-surgical moments are required to install the temporary acrylic prosthesis, associated with the non-welded bar, and to put it into operation. In addition, the opportunity of not using welds or cement to join the cylinders to the bar offers effective results at a low cost, showing simplicity and speed. Due to its mechanical properties, the metal reinforced temporary acrylic prosthesis may be used for a longer period beyond the scarring period, and may also be used as a lower cost final prosthesis ${ }^{3,12}$.

This study presented limitations, especially due to the low number of samples tested and due to the fact that it was an in vitro study. In vivo longitudinal studies are warranted to achieve clinical results that allow for a comparison to this in vitro study.

\section{CONCLUSION}

Results have confirmed that the metal reinforcement increased the final resistance of temporary acrylic prostheses. The connection resin interface between the metal bar and the cylinders increased the resistance to the bending load.

\section{REFERENCES}

1. Van de Velde T, Collaert B, De Bruyn H. Immediate loading in the completely edentulous mandible: technical procedure and clinical results up to 3 years of functional loading. Clin Oral Implants Res. 2007 Jun;18(3):295-303. http://dx.doi.org/10.1111/j.1600-0501.2007.01340.x. PMid:17386064.

2. Maló P, Nobre MA, Lopes A, Moss SM, Molina GJ. A longitudinal study of the survival of All-on-4 implants in the mandible with up to 10 years of follow-up. J Am Dent Assoc. 2011 Mar;142(3):310-20. http://dx.doi.org/10.14219/jada.archive.2011.0170. PMid:21357865.

3. Maló P, Rangert B, Nobre M. "All-on-Four" immediate-function concept with Brånemark system ${ }^{\circledR}$ implants for completely edentulous mandibles: a retrospective clinical study. Clin Implant Dent Relat Res. 2003;5(Suppl 1):2-9. http://dx.doi.org/10.1111/j.1708-8208.2003.tb00010.x. PMid:12691645.

4. Correa S, Ivancik J, Isaza JF, Naranjo M. Evaluation of the structural behavior of three and four implantsupported fixed prosthetic restorations by finite element analysis. J Prosthodont Res. 2012 Apr;56(2):110-9. http://dx.doi.org/10.1016/j.jpor.2011.07.001. PMid:22104623.

5. Hinze $\mathrm{M}$, Thalmair $\mathrm{T}$, Bolz $\mathrm{W}$, Wachtel $\mathrm{H}$. Immediate loading of fixed provisional prostheses using four implants for the rehabilitation of the edentulous arch: a prospective clinical study. Int J Oral Maxillofac Implants. 2010 Sep-Oct;25(5):1011-8. PMid:20862417.

6. Begg T, Geerts GA, Gryzagoridis J. Stress patterns around distal angled implants in the all-on-four concept configuration. Int J Oral Maxillofac Implants. 2009 Jul-Aug;24(4):663-71. PMid:19885406. 
7. Ferreira EJ, Kuabara MR, Gulinelli JL. "All-on-four" concept and immediate loading for simultaneous rehabilitation of the atrophic maxilla and mandible with conventional and zygomatic implants. Br J Oral Maxillofac Surg. 2010 Apr;48(3):218-20. http://dx.doi.org/10.1016/j.bjoms.2009.08.017. PMid:19767132.

8. Khatami AH, Smith CR. "All-on-Four" immediate function concept and clinical report of treatment of an edentulous mandible with a fixed complete denture and milled titanium framework. J Prosthodont. 2008 Jan;17(1):47-51. http://dx.doi.org/10.1111/j.1532-849X.2007.00246.x. PMid:17931367.

9. Agliardi E, Panigatti S, Clericò M, Villa C, Maló P. Immediate rehabilitation of the edentulous jaws with full fixed prostheses supported by four implants: interim results of a single cohort prospective study. Clin Oral Implants Res. 2010 May;21(5):459-65. http://dx.doi.org/10.1111/j.16000501.2009.01852.x. PMid:20105197.

10. Francetti L, Agliardi E, Testori T, Romeo D, Taschieri S, Del Fabbro M. Immediate rehabilitation of the mandible with fixed full prosthesis supported by axial and tilted implants: interim results of a single cohort prospective study. Clin Implant Dent Relat Res. 2008 Dec;10(4):255-63. http://dx.doi.org/10.1111/j.1708-8208.2008.00090.x. PMid:18384405.

11. Ogawa T, Dhaliwal S, Naert I, Mine A, Kronstrom M, Sasaki K, et al. Impact of implant number, distribution and prosthesis material on loading on implants supporting fixed prostheses. J Oral Rehabil. 2010 Jul;37(7):525-31. http://dx.doi.org/10.1111/j.1365-2842.2010.02076.x. PMid:20236236.

12. Degidi M, Nardi D, Piattelli A. Prospective study with a 2-year follow-up on immediate implant loading in the edentulous mandible with a definitive restoration using intra-oral welding. Clin Oral Implants Res. 2010 Apr;21(4):379-85. http://dx.doi.org/10.1111/j.1600-0501.2009.01865.x. PMid:20128829.

13. Yilmaz B, Suarez C, McGlumphy E. Correction of misfit in a maxillary immediate metal-resin implantfixed complete prosthesis placed with flapless surgery on four implants. Int J Oral Maxillofac Implants. 2011 Sep-Oct;26(5):e23-8. PMid:22010097.

14. Borges AF, Pereira LAD, Thomé G, Melo AC, Sartori IAM. Prostheses removal for suture removal after immediate load: success of implants. Clin Implant Dent Relat Res. 2010 Sep;12(3):244-8. http://dx.doi.org/10.1111/j.1708-8208.2009.00157.x. PMid:19438945.

15. Engstrand P, Gröndahl K, Öhrnell LO, Nilsson P, Nannmark U, Branemark PI. Prospective follow-up study of 95 patients with edentulous mandibles treated according to the Brånemark Novum concept. Clin Implant Dent Relat Res. 2003;5(1):3-10. http://dx.doi.org/10.1111/j.1708-8208.2003.tb00176.x. PMid:12831723.

16. Landázuri-Del Barrio RA, Cosyn J, De Paula WN, De Bruyn H, Marcantonio E Jr. A prospective study on implants installed with flapless-guided surgery using the all-on-four concept in the mandible. Clin Oral Implants Res. 2013 Apr;24(4):428-33. http://dx.doi.org/10.1111/j.1600-0501.2011.02344.x. PMid:22092825.

17. Inman DJ. Engineering vibrations. 3rd ed. Upper Saddle River: Prentice Hall; 2007.

18. Nikellis I, Levi A, Nicolopoulos C. Immediate loading of 190 endosseous dental implants: a prospective observational study of 40 patient treatments with up to 2-year data. Int J Oral Maxillofac Implants. 2004 Jan-Feb;19(1):116-23. PMid:14982364.

19. Wiskott HW, Nicholls JI, Belser UC. Stress fatigue: basic principles and prosthodontic implications. Int J Prosthodont. 1995 Mar-Apr;8(2):105-16. PMid:7575960.

20. Kim KS, Kim YL, Bae JM, Cho HW. Biomechanical comparison of axial and tilted implants for mandibular full-arch fixed prostheses. Int J Oral Maxillofac Implants. 2011 Sep-Oct;26(5):976-84. PMid:22010079.

21. Albakry M, Guazzato M, Swain MV. Biaxial flexural strength elastic moduli, and x-ray diffraction characterization of three prenssable all-ceramic materials. J Prosthet Dent. 2003 Apr;89(4):374-80. http://dx.doi.org/10.1067/mpr.2003.42. PMid:12690350. 
22. Benazzi S, Kullmer O, Grosse IR, Weber GW. Using occlusal wear information and finite element analysis to investigate stress distributions in human molars. J Anat. 2011 Sep;219(3):259-72. http://dx.doi.org/10.1111/j.1469-7580.2011.01396.x. PMid:21615398.

23. Mericske-Stern R, Zarb GA. In vivo measurements of some functional aspects with mandibular fixed prostheses supported by implants. Clin Oral Implants Res. 1996 Jun;7(2):153-61. http://dx.doi.org/10.1034/j.1600-0501.1996.070209.x. PMid:9002834.

24. Brunski JB, Puleo DA, Nanci A. Biomaterials and biomechanics of oral and maxillofacial implants: current status and future developments. Int J Oral Maxillofac Implants. 2000 Jan-Feb;15(1):15-46. PMid:10697938.

25. Mostafa TM, Elgendy MN, Kashef NA, Halim MM. Evaluation of the precision of three implant transfer impression techniques using two elastomeric impression materials. Int J Prosthodont. 2010 NovDec;23(6):525-8. PMid:21209987.

26. Drago CJ, Lazzara RJ. Immediate occlusal loading of Osseotite implants in mandibular edentulous patients: a prospective observational report with 18-month data. J Prosthodont. 2006 MayJun;15(3):187-94. http://dx.doi.org/10.1111/j.1532-849X.2006.00099.x. PMid:16681501.

\section{CONFLICTS OF INTERESTS}

The authors declare no conflicts of interest.

\section{${ }^{*}$ CORRESPONDING AUTHOR}

Vanessa Araujo Silva, PUC Minas - Pontifícia Universidade Católica de Minas Gerais, Departamento de Odontologia, Avenida D. José Gaspar, 500, Prédio 46, Sala 101, Coração Eucarístico, 30535-901 Belo Horizonte - MG, Brasil, e-mail: vanessa.araujos@icloud.com

Received: November 22, 2018

Accepted: May 6, 2019 